\title{
Design de tecnologia e educação inclusiva: explorando o espaço do problema
}

\author{
Leonara de Medeiros Braz ${ }^{1}$, Eliane de Souza Ramos ${ }^{23}$, Maria Luisa \\ Pozzebom Benedetti ${ }^{3}$, Heiko Horst Hornung ${ }^{1}$ \\ ${ }^{1}$ Instituto de Computação - Universidade Estadual de Campinas (Unicamp) \\ Av ALbert Einstein, 1251 - 13.083-852 - Campinas-SP - Brasil \\ ${ }^{2}$ Faculdade de Educação - Universidade Estadual de Campinas (Unicamp) \\ Rua Bertrand Russell, 801 - 13.083-865 - Campinas-SP - Brasil \\ ${ }^{3}$ Secretaria Municipal de Educação - Prefeitura Municipal de Amparo \\ Rua Bernardino de Campos, 705 - 13.900-400 - Amparo-SP - Brasil \\ \{leonarabraz, souzaramos80\}@gmail.com, mlpbenedetti@amparo.sp.gov.br, \\ heikodic.unicamp.br
}

\begin{abstract}
Technologies are increasingly used as mediators of the teaching and learning process. The Tangible User Interface is an example of such technology. Every student is unique, however, many of the works seen in the literature are targeted at a very specific audience. In this work we seek to understand how to design technological resources that can be used in inclusive education by teachers and students regardless of their needs and abilities. In this paper we describe the methodology used and report the first workshops already held introducing participatory design implications of Tangible User Interfaces in inclusive educational contexts.
\end{abstract}

Resumo. Tecnologias são cada vez mais utilizadas como mediadoras do processo de ensino e aprendizagem. A Interface de Usuário Tangível é uma dessas tecnologias. Todo aluno é um ser único, porém, muitos dos trabalhos vistos na literatura são voltados para um público-alvo muito específico. Neste trabalho buscamos entender como desenhar recursos tecnológicos que possam ser utilizados na educação inclusiva por professores e alunos independente de suas necessidades e habilidades. Neste artigo descrevemos a metodologia utilizada e relatamos as primeiras oficinas já realizadas apresentando implicações de design participativo de Interfaces de Usuário Tangíveis em contextos educacionais inclusivos.

\section{Introdução}

Um dos aspectos a serem considerados na transformação das escolas comuns brasileiras em instituições mais inclusivas é o trabalho com recursos e tecnologias contemporâneas. Isto porque tais recursos e tecnologias podem minimizar e até mesmo eliminar algumas barreiras que impedem pessoas com deficiência de conviver e de aprender com seus colegas e professores, conforme constroem a sua formação acadêmica e cidadã em escolas comuns.

Como mostrado por [Moreira e Baranauskas 2015], muitos trabalhos de pesquisa têm como objetivo estudar como a tecnologia pode afetar, de forma positiva, as pessoas 
V Congresso Brasileiro de Informática na Educação (CBIE 2016)

Anais do XXVII Simpósio Brasileiro de Informática na Educação (SBIE 2016)

com deficiência na realização de suas atividades cotidianas, no ensino e no aprendizado. Observamos que existem vários métodos e tecnologias que têm sido utilizados para este fim. Uma destas tecnologias é a Interface de Usuário Tangível (TUI, do inglês Tangible User Interface).

A TUI vai além da interface gráfica e dos tradicionais dispositivos de entrada de dados (mouse, teclado). Ela permite que os usuários usem e manipulem objetos físicos e essa interação/manipulação é tratada como entrada ou saída da aplicação.

[Zuckerman et al. 2005] listam três vantagens da utilização de interfaces tangíveis, que são: (i) a TUI se insere no ambiente do usuário; (ii) utiliza vários sentidos do usuário - visão, tato, audição - produzindo, assim, um engajamento sensorial; e (iii) a TUI pode oferecer maior acessibilidade, já que os usuários com deficiência podem apresentar dificuldades ainda não previstas na utilização de computadores comuns. Exemplo: uma pessoa com deficiência física pode encontrar dificuldades para mover um mouse ou digitar em um teclado comum.

Pautar o trabalho com recursos e tecnologias contemporâneas na ideia de que todo aluno é um ser único que se atualiza constantemente, nos coloca diante de um grande desafio. Desafio este que temos vivido dia após dia na tentativa de projetar um material que ganhe determinada forma e passe a ter chance de ser trabalhado, por professores de educação especial que atendem alunos com deficiência, transtornos no desenvolvimento, altas habilidades e superdotação.

Tal desafio nos faz entender alguns dos motivos que levam pesquisadores e professores a optarem pela tecnologia assistiva [Galvão Filho 2012], visto que esta é muito focada, projetada e específica. A tecnologia assistiva é criada para atender a uma determinada necessidade em um contexto pré-definido. Identificamos também que muitas TUIs realizam o papel de uma tecnologia assistiva e/ou são construídas com um objetivo educacional e um público-alvo muito específicos.

Entretanto, acreditamos que o trabalho com recursos e tecnologias contemporâneas no contexto educacional deve dedicar seus esforços na identificação e no entendimento não só daquilo que se refere às necessidades consequentes da condição de deficiência de alguns alunos, mas fundamentalmente, nas barreiras existentes (e produzidas) na escola que pouco contribuem para que a inclusão seja o resultado de todos os atos daqueles que desta escola fazem parte. Outrossim, nem sempre este professor dispõe de conhecimentos suficientes que garantirão o bom funcionamento dos equipamentos com os quais são desafiados a trabalhar no Atendimento Educacional especializado (AEE).

Diante disso, uma pergunta relevante é: como desenhar recursos tecnológicos que possam ser utilizados na educação inclusiva por professores e alunos que inicialmente são leigos no uso dessas tecnologias, considerando e respeitando as diferentes necessidades, capacidades e preferências dos professores, alunos e demais partes interessadas?

Para minimizar a necessidade de aprender a trabalhar com distintas tecnologias, um requisito essencial é que, diferente da tecnologia assistiva "tradicional", tais recursos sejam flexíveis o suficiente para acomodar diferentes necessidades apresentadas pelos alunos, atendidos pelo professor de educação especial, e diferentes objetivos educacionais. Para promover um uso autônomo pelos professores, nossa hipótese é que o processo de design destes recursos deve ser participativo e envolver diferentes partes interessadas, 
V Congresso Brasileiro de Informática na Educação (CBIE 2016)

Anais do XXVII Simpósio Brasileiro de Informática na Educação (SBIE 2016)

desde a concepção até o uso da tecnologia.

Neste artigo, relatamos nossas experiências das fases iniciais de um processo de design participativo de TUIs que podem promover a educação inclusiva. Embora existam exemplos de TUIs na literatura, que segundo seus autores foram desenhadas participativamente, pouco se encontra sobre como foi conduzido o processo de design, e menos ainda como foram conduzidos os primeiros passos deste processo.

A contribuição deste artigo, portanto é identificar e discutir implicações de design de TUIs em contextos educacionais inclusivos, visando proporcionar um uso autônomo pelos professores. Para isso, utilizamos a técnica de design participativo e promovemos a articulação entre os conhecimentos do campo educacional, possível pela participação efetiva das professoras de educação especial, e da ciência da computação. Isto porque, desejamos que o artefato projetado não seja somente mais uma tecnologia que foi adquirida por estas professoras.

O artigo está organizado da seguinte forma: seção 2 que descreve o contexto em que a pesquisa está situada: o Atendimento Educacional Especializado (AEE; um atendimento no contexto da educação inclusiva nas escolas públicas brasileiras) e como este atendimento está instanciado no município parceiro em que conduzimos as práticas de design; seção 3 que descreve o método empregado; seção 4 que apresenta os resultados e sua análise; seção 5 que discute implicações para o design e seção 6 na qual expusemos algumas considerações finais.

\section{O Atendimento Educacional Especializado}

A Política Nacional de Educação Especial na Perspectiva Inclusiva (2008) é clara na definição do que vem a ser o Atendimento Educacional Especializado (AEE). Trata-se de um atendimento que deve ser realizado por um professor de educação especial que identificará quais são as barreiras existentes na escola comum, que impedem ou dificultam a convivência, a comunicação, as interações e os processos educativos e pedagógicos dos alunos com deficiência, transtornos do desenvolvimento, altas habilidades e superdotação.

Para identificar estas barreiras, este professor precisa atender o aluno em um espaço específico chamado Sala de Recursos Multifuncionais (SRM), no turno contrário ao de suas aulas. Além disso, o professor de AEE precisa conhecer os professores da classe comum do aluno atendido, demais alunos, o espaço físico, os recursos didáticos, pedagógicos de informática e outros, disponíveis na escola comum.

O professor de AEE deve realizar um estudo sobre a dinâmica de trabalho da turma da qual faz parte o aluno em atendimento, na sua escola. Trata-se então, de uma educação especial que contempla demandas locais relacionadas à acessibilidade e que impulsiona a inclusão nas escolas.

A escola inclusiva reconhece e considera que todos os alunos são capazes de se desenvolver e de aprender e que este é o ponto de partida para a criação do ensino que se faz. O professor na escola inclusiva deve oportunizar um ensino enriquecido com diferentes materiais, tecnologias, recursos, estratégias educacionais e pedagógicas, ampliando as possibilidades dos alunos se sentirem afetados pelos conteúdos que ensina e possam atualizá-los, cada um à sua maneira. 
V Congresso Brasileiro de Informática na Educação (CBIE 2016)

Anais do XXVII Simpósio Brasileiro de Informática na Educação (SBIE 2016)

\subsection{O AEE no Município de Amparo-SP}

Embasados nas políticas públicas vigentes, a inclusão escolar no município de Amparo, no interior de São Paulo, parceiro com o qual temos desenvolvido este estudo, iniciou os primeiros estudos sobre educação inclusiva a partir de 2001. No ano de 2006 implantou o Programa "A educação tem muitas faces - educando e aprendendo na diversidade", desenvolvido pela Secretaria Municipal de Educação, cujo objetivo é garantir a todos os alunos o direito ao acesso e permanência qualificados na rede comum de ensino.

No decorrer destes anos o Programa de Educação Inclusiva da Rede Municipal de Amparo vem se aperfeiçoando no sentido de continuar desenvolvendo ações para a construção de uma sociedade mais justa, que respeite e valorize as diferentes condições físicas, psíquicas, mentais, culturais e econômicas de todas as pessoas.

O município, através do Programa de Implantação de Salas de Recursos Multifuncionais (SRM), instituído pelo MEC/SECADI por meio da Portaria Ministerial $\mathrm{n}^{\mathrm{o}}$ 13/2007, integra o Plano de Desenvolvimento da Educação - PDE e o Plano Nacional dos Direitos da Pessoa com Deficiência - Viver sem Limite, organizou o primeiro espaço físico, chamado de Sala de Recursos Multifuncionais, em 2008 para a organização dos equipamentos, mobiliários e materiais didáticos e pedagógicos de acessibilidade, bem como, o professor para trabalhar no AEE. Após a organização deste espaço outras Salas de Recursos Multifuncionais foram sendo implementadas ao longo destes anos, totalizando atualmente quatro salas em diferentes pontos do município, com quatro professoras da educação especial, que atendem todas as escolas municipais nos níveis de ensino que possui.

Cada professor atende atualmente, em média, dezessete alunos nos dois tipos de atendimento: com o aluno na Sala de Recursos Multifuncionais e para este aluno, em que os professores de AEE identificam estratégias, procedimentos, tecnologias, e recursos especializados a serem utilizados pelos alunos atendidos no ensino comum. Vale ressaltar que todos os alunos da Rede Municipal que têm direito ao AEE o recebem.

\section{Método de Pesquisa}

No presente trabalho utilizamos um modelo iterativo de Design da Interação composto por cinco passos: entender, estudar, desenhar, construir e avaliar [Harper 2008]. O processo é conduzido de forma participativa [Jacko 2012]. As atividades de design são norteadas pelos ideais do Design Universal ou Design para Todos [Stephanidis e Savidis 2001].

No momento da escrita deste trabalho, os participantes no processo de design são uma mestranda em Ciência de Computação pela Universidade Estadual de Campinas e seu orientador, a Coordenadora do Programa de Educação Inclusiva do município Amparo, a Assessora Técnica e Pedagógica, e quatro professoras do Atendimento Educacional Especializado do mesmo município. Futuramente esperamos que outras partes interessadas participem do processo, por exemplo, professores das salas comuns e alunos.

As atividades principais são conduzidas nas escolas das professoras participantes, aproximadamente uma vez por mês, respeitando a disponibilidade dos envolvidos. Atividades secundárias, por exemplo, análise de dados e preparação das atividades principais, são conduzidas na UNICAMP. No Design Participativo é importante que os envolvidos tenham voz. Tentamos alcançar este ideal através da coautoria deste artigo do qual são 
V Congresso Brasileiro de Informática na Educação (CBIE 2016)

Anais do XXVII Simpósio Brasileiro de Informática na Educação (SBIE 2016)

autores: a coordenadora, assessora, mestranda e seu orientador; as professoras são representadas através de citações das suas falas. A pesquisa foi aprovada pelo Comitê de Ética em Pesquisa da UNICAMP (CAAE: 50836815.5.0000.5404).

As atividades iniciais da mestranda e seu orientador para entender e estudar o contexto incluíram visitas dos locais (i.e., escolas e SRMs nelas) com conversas com as professoras e observações de AEE. Dados coletados nestes passos foram anotados em papel.

Em seguida conduzimos oficinas de aproximadamente duas horas, uma vez por mês, com todos os participantes. Neste artigo analisamos e discutimos as primeiras duas oficinas. O ponto de partida para ambas foram protótipos de TUIs criados pela mestranda. Estes protótipos serviram como base de discussão e demais atividades, para clarificar e construir colaborativamente o contexto e as possibilidades de design. Dados coletados nestas atividades foram anotados em papel, roteiros de perguntas e suas respostas, os protótipos criados e gravações de vídeos que foram transcritos.

Para a criação dos protótipos escolhemos o kit MakeyMakey ${ }^{1}$ como plataforma de hardware. Esse kit é composto por uma placa de circuito, garras jacaré para conectar objetos condutivos à placa e um cabo USB para conectar a placa ao computador. O dispositivo age como Human Interface Device, i.e., gerando eventos de teclado ou mouse. Dessa forma objetos do cotidiano (por exemplo, frutas, desenhos à lápis, ou qualquer objeto condutivo) podem ser utilizados como dispositivos de entrada no computador. Lembrando que um dos nossos objetivos é desenhar TUIs que promovam o uso autônomo por professores e alunos, decidimos utilizar esse artefato pela simplicidade de uso e pelo seu potencial de proporcionar uma facilidade na adaptação de atividades envolvendo o computador.

\section{Resultados e Análise}

\subsection{Visitas Exploratórias}

Realizamos visitas para compreender o trabalho de professores de AEE. Buscamos entender como são realizados os atendimentos nas SRM. Nestas visitas, vimos quais materiais são utilizados, quais as limitações desses recursos e quais as maiores necessidades das professoras para a relaização dos atendimentos. Em uma visita posterior, fizemos uma breve apresentação do que são TUIs e como o MakeyMakey funciona, levando um exemplo simples de TUI - fichinhas de papelão e folha alumínio e fizemos uma sessão de discussão sobre como a TUI pode ser inserida nescola comum inclusiva.

Posteriormente fizemos uma visita para observar como os atendimentos são feitos. Observamos dois atendimentos de diferentes crianças. Antes e depois dos atendimentos conversamos com as respectivas professoras para nos contextualizar e entender que tipo de trabalho estava sendo feito. O primeiro atendimento observado foi com uma criança de 9 anos de idade que tem perda auditiva, poucas habilidades de fala, e está no processo de aprender a Língua Brasileira de Sinais (Libras). O segundo atendimento observado foi com uma criança que tem paralisia cerebral e possui deficiência múltipla. Essa criança possui movimentos involuntários, não fala, gesticula ou aponta. Segundo a professora de AEE, a única ação voluntária da criança é a produção de alguns sons.

\footnotetext{
${ }^{1}$ http://www . makeymakey.com/
} 
V Congresso Brasileiro de Informática na Educação (CBIE 2016)

Anais do XXVII Simpósio Brasileiro de Informática na Educação (SBIE 2016)

\subsection{Oficina 1}

Como as professoras ainda tinham um conhecimento limitado sobre tecnologias tangíveis, decidimos iniciar nossas oficinas levando um protótipo funcional, mostrando uma aplicação TUI para iniciar a discussão. Como os pesquisadores de computação tinham poucos conheimentos sobre as atividades realizadas no AEE, o portótipo foi baseado em uma atividade realizada pelas professoras, que é a contação de história, na qual elas utilizam uma placa de metal e cartões em imã.

Desenvolvemos um protótipo de baixa tecnologia, composto por uma "prancha de interação" de papelão e papel alumínio (Figura 1), uma aplicação feita com $\mathrm{Scratch}^{2}$ e o MakeyMakey para conectar a prancha à aplicação. A atividade que desenvolvemos para a utilização desse protótipo se deu a partir da rotina da manhã: desde acordar até ir para a escola. Segundo as professoras, rotinas (por exemplo, escovar os dentes, ir ao banheiro, trocar de roupas, ir à escola) são trabalhadas em vários momentos nos atendimentos, no sentido de identificar o melhor recurso para que seja inserido no ensino comum. $O$ objetivo da primeira oficina foi explorar se/como o protótipo poderia ser apropriado e se as professoras conseguiriam visualizar outras atividades sendo realizadas com o modelo de protótipo proposto.

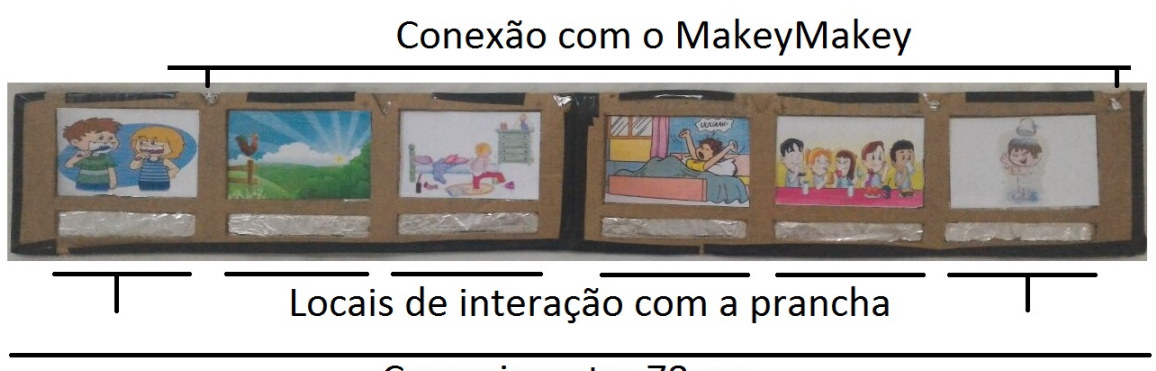

Comprimento: $78 \mathrm{~cm}$

Figura 1. Prancha para interação com explicação dos seus componentes.

O protótipo possui uma área onde os professores podem inserir imagens a serem trabalhadas com as crianças, uma área onde ocorre a interação da criança com a aplicação e pontos para conectar o MakeyMakey. A interação com o recurso é feita através do toque. Ao tocar em determinada área, se essa for a opção correta, a aplicação realiza uma ação, caso contrário, retorna uma mensagem sonora de erro.

Na realização da oficina, fizemos uma dinâmica de acting, na qual dividimos os participantes em três duplas e cada integrante da dupla representou um professor e um aluno. Com essa dinâmica, queríamos ver como a prancha se comportava na realização da atividade. Ao final, fizemos uma discussão geral sobre o modelo de interface tangível proposto. As professoras se sentiram bem à vontade na realização da oficina, comentando cada interação e discutindo possíveis soluções.

Um fato que incomodou as professoras foi uma peculiaridade inerente do MakeyMakey, que é a necessidade de fechar um circuito elétrico para gerar o evento de teclado/mouse. Um jeito comum é afixar um fio ao corpo do usuário ou pedir que ele/a o segure. No contexto do AEE isso parece pouco viável: por exemplo, há crianças que se

\footnotetext{
${ }^{2}$ https: / / scratch.mit.edu/
} 
V Congresso Brasileiro de Informática na Educação (CBIE 2016)

Anais do XXVII Simpósio Brasileiro de Informática na Educação (SBIE 2016)

incomodam com coisas afixadas no corpo, e falantes de Libras precisam das duas mãos livres para se comunicar. Uma sugestão feita pelas professoras foi a criação de algo vestível, na qual a criança "nem perceberia que estaria usando" ou não teria a possibilidade de retirá-lo do corpo. Outra crítica foi que a área de interação era muito pequena $(1 \mathrm{~cm}$ de largura), o que dificultaria a interação de alguns alunos com o dispositivo.

Sobre o modelo da prancha, elas perguntaram se daria para ser fichas separadas, pois "as vezes você precisa trabalhar com três [opções] só, e não com muitas". Propuseram, também, "ter opção de não ser essa sequência obrigatória".

A aplicação tinha uma sequência fixa, não possibilitando o erro. As professoras informaram que permitir o erro é bom e necessário, pois o professor comum pode trabalhar com as diferentes respostas do seu aluno: "você não tem um enfoque em 'está errado', você pede para a criança pensar".

Uma lição aprendida nesta oficina refere-se ao planejamento e à execução das atividades. Apesar de ter um planejamento e uma estrutura para as atividades tivemos dificuldade em segui-los, pois as professoras foram muito participativas, ora adiantando questões, ora voltando a itens já discutidos. Com isso em mente, buscamos estruturar a Oficina 2 alavancando a participação das professoras sem perder o foco das atividades. Para isso, utilizamos uma atividade maior com uma lista de tópicos a serem trabalhados, ao invés de atividades menores e mais estruturadas. Adicionalmente usamos um cartaz onde professoras registraram suas ideias e contribuições de forma escrita.

\subsection{Oficina 2}

Baseado nas análises dos resultados da Oficina 1, a primeira autora criou um novo protótipo, possibilitando uma forma de interação diferente. O protótipo é composto por duas partes: uma prancha e seis cartões. A prancha foi feita inspirada em jogos de quebra cabeça, possibilitando o encaixe dos cartões. O protótipo é de baixa tecnologia, feito com isopor e papel alumínio (Figura 2).

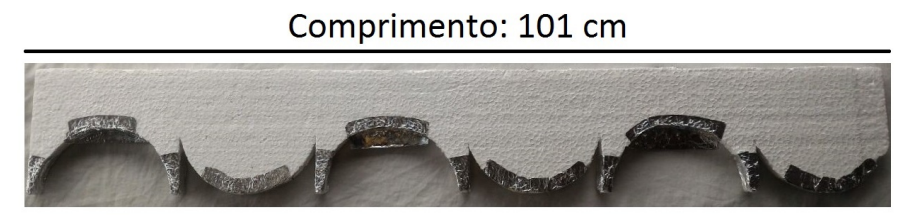

(a)

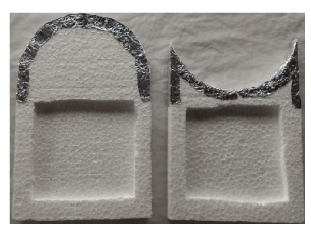

(b)

Figura 2. Componentes do segundo modelo de prancha de comunicação.

Na prancha, a ponta e o centro das seis áreas tem um revestimento de papel alumínio. A parte posterior da prancha tem sete cavidades para a conexão com o MakeyMakey (Figura 3). Os cartões de isopor tiveram a sua borda superior toda revestida de papel alumínio, para que, ao entrar em contato com a prancha, feche o circuito e realize a ação relacionada à este evento. Cada cartão possui uma área para a inserção de imagens, assim os mesmos podem ser customizados pelo professor.

Para esta oficina, fizemos um quadro de anotação, para instigar as professoras a escrever suas ideias. Esta técnica foi utilizada, pois muitas vezes em entrevistas ou discussões, os participantes fazem vários levantamentos, porém, o pesquisador pode não 
V Congresso Brasileiro de Informática na Educação (CBIE 2016)

Anais do XXVII Simpósio Brasileiro de Informática na Educação (SBIE 2016)

compreender a mensagem da forma que o participante gostaria de ser entendido. Assim, foi pedido que as participantes, ao terem uma ideia, questionamento ou solução, escrevessem no quadro.

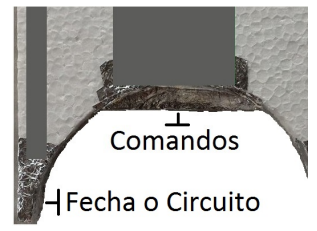

(a)

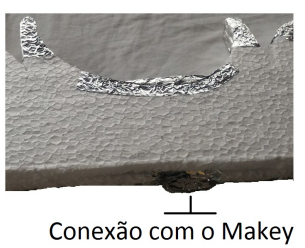

(b)

Figura 3. Organização dos circuitos na parte interna da prancha (a); pontos de conexão com o MakeyMakey (b).

As professoras sugeriram permitir a mudança do sentido da prancha: "Essa placa a gente só consegue usar nessa posição [horizontal]? Colocar ela em pé, não é possível?". Outra sugestão era deixar a prancha maleável, que possa ser dobrada, ocupando menos espaço, e que seja fácil de guardar.

Um objetivo importante do nosso trabalho é facilitar o uso autônomo das tecnologias criadas. Nesta segunda oficina, as professoras começaram a questionar sobre os benefícios da utilização de tal tecnologia. Pensaram como apropriar a tecnologia proposta para suas atividades, por exemplo: "Vai ser só mais uma opção para fazer a mesma coisa?" - "Qual seria o diferencial?" - "Como eu posso me apropriar do artefato e o que ele pode me proporcionar de diferente?". Interpretamos essas manifestações como evidências de que a abordagem participativa promove a apropriação pelas professoras e facilita um futuro uso autônomo.

\section{Discussão - Implicações para o Design}

Nessa seção discutimos implicações para o design. Essa discussão é útil para partes interessadas em processos de pesquisa e design que gostariam de utilizar o MakeyMakey em seus projetos, criar TUIs utilizando processos participativos e inclusivos, ou desenhar soluções a serem utilizados no AEE ou em classes comuns.

O MakeyMakey já vem sendo utilizado para criar TUIs em contextos educacionais (por exemplo, [Goya et al. 2012], [Hamidi et al. 2014] e [Lin e Chang 2014]). Porém, muitos trabalhos focam em atividades educacionais específicas e não deixam evidente se houve uma preocupação com um design inclusivo ou o uso autônomo pelo professor. Somente no trabalho de [Goya et al. 2012] percebemos a preocupação com um design acessível, permitindo que o maior número de pessoas, independentemente de suas habilidades, possa uzá-la. Neste sentido, nosso trabalho representa um diferencial.

Uma limitação técnica do MakeyMakey é a necessidade de fechar um circuito elétrico. No protótipo usado na oficina 2 encontramos uma solução para esta limitação, utilizando o modo de interação "encaixar um objeto em outro objeto". Porém, existem outras configurações onde essa solução não é possível, por exemplo, em um modo de interação onde se deve "tocar um objeto".

Outra limitação é que o MakeyMakey dispara um conjunto limitado de eventos (apertar e soltar as teclas). Isso limita o modo e o fluxo de interação. Nos protótipos ex- 
V Congresso Brasileiro de Informática na Educação (CBIE 2016)

Anais do XXVII Simpósio Brasileiro de Informática na Educação (SBIE 2016)

ploramos os modos "tocar objeto" e "encaixar objeto" e os fluxos "se isso então aquilo" e "sequência fixa". Esta limitação tem dois aspectos positivos. Do ponto de vista de design, limitações podem resultar em soluções criativas. Do ponto de vista de customização, apropriação e uso, usuários não se sentem sobrecarregados com inúmeras possibilidades de uma tecnologia menos limitada.

Enxergamos este último ponto como o mais forte do MakeyMakey. Pela simplicidade e as limitações, é um recurso que pode ser usado sem ser "programado" e que proporciona às professoras uma facilidade na apropriação de artefatos, podendo escolher os objetos que desejam utilizar e moldá-los de acordo com seus interesses.

O AEE e as práticas de professores nas SRM e nas salas comuns parecem ser muito bem alinhados com o Design Participativo e o Design para Todos como entendidos e praticados na área de Interação Humano-Computador. Nas oficinas apresentadas neste artigo isso se mostrou na facilidade de desenvolver atividades juntando pessoas com diferentes conhecimentos. A confecção e adaptação de recursos do AEE e as trocas entre professores da SRM e da sala comum correspondem a práticas iterativas e participativas de design.

O AEE atende alunos de diferentes idades e com diferentes necessidades. As atividades realizadas nas Salas de Recursos Multifuncionais são diversas. Isso indica que nossa abordagem de desenvolver uma tecnologia que possa ser utilizada por diferentes alunos e diferentes atividades é adequada. Além disso, uma abordagem participativa parece necessária, pois diferentes tipos de conhecimento são necessários para desenhar os artefatos desejados.

Um desafio que emerge neste contexto é relacionado à prototipação. Embora um usuário de uma interface gráfica tradicional talvez possa imaginar e desenhar/esboçar uma nova interface, nas fases iniciais de um projeto, uma pessoa sem experiência em design provavelmente tem dificuldades de imaginar as possibilidades de uma TUI. Isso dificulta o uso de práticas participativas. No outro lado, os "designers" ainda tem pouco conhecimento das práticas do AEE, o que dificulta a geração de propostas de protótipos.

Protótipos de baixa fidelidade, como protótipos em papel e storyboards não abrangem todos os detalhes do design, especialmente no caso de TUIs que proporcionam modos de interação diferentes. Isso apresenta um desafio para a discussão e avaliação dos protótipos, pois participantes sem experiência em design e com TUIs podem não enxergar limitações ou potenciais importantes. Por isto, optamos inicialmente por criar protótipos de maior fidelidade, usando técnicas como Wizard of $O z$ e aplicações simples desenvolvidas no Scratch.

Desenvolver protótipos funcionais de maior fidelidade ao invés de apenas entrevistar os participantes ou fazer visitas exploratórias, é importante, pois os mesmos apoiam a discussão do modelo conceitual do produto. Além disso, as oficinas revelaram aspectos das práticas que não foram mencionadas em conversas, entrevistas ou visitas exploratórias. Isso mostra que a prototipação não é só instrumental para o design, mas necessária para a clarificação do contexto. 
V Congresso Brasileiro de Informática na Educação (CBIE 2016)

Anais do XXVII Simpósio Brasileiro de Informática na Educação (SBIE 2016)

\section{Conclusão}

Existe uma crescente demanda de tecnologias em escolas comuns. Muitos trabalhos de pesquisa têm como objetivo estudar como a tecnologia pode afetar, de forma positiva, o ensino. Existem vários métodos e tecnologias que têm sido utilizados para este fim. Uma destas tecnologias é a TUI. Porém muitos dos trabalhos que utilizam tal tecnologia focam em atividades educacionais muito específicas e são voltados para um público-alvo muito específico.

Todavia, todo aluno é um ser único que se atualiza constantemente. Outro fator que deve ser considerado é que nem sempre o professor dispõe de conhecimentos suficientes para utilizar tais tecnologias. Este trabalho buscou mostrar as implicações de design participativo de TUIs em contextos educacionais inclusivos.

Devido às características do AEE e público-alvo que frequenta o AEE, o modelo de design participativo se mostra muito promissor. Apesar de permitir que os participantes tenham muita liberdade na execução das oficinas, é importante ter um planejamento cuidadoso da execução das atividades. Sobre a tecnologia utilizada, apesar das suas limitações técnicas e um número limitado de recursos, o MakeyMakey, por sua facilidade de uso e potencial de apropriação, parece uma base tecnológica adequada para o design de TUIs que permitem um uso autônomo pelos professores.

\section{Referências}

Galvão Filho, T. A. (2012). http: / / www • planetaeducacao.com.br/portal / artigo. asp?artigo=2430. Acesso em: 25/06/2015.

Goya, J., Bonfim, G., Yonashiro, M., and Paschoarelli, L. (2012). Criação e desenvolvimento de um controlador de jogos eletrônicos: Um projeto inclusivo. XI SBGames.

Hamidi, F., Baljko, M., Kunic, T., and Feraday, R. (2014). Do-it-yourself (diy) assistive technology: A communication board case study. In Computers Helping People with Special Needs, pages 287-294. Springer.

Harper, R. H. (2008). Being human: Human-computer interaction in the year 2020. Microsoft Research Limited.

Jacko, J. A. (2012). Human Computer Interaction Handbook: Fundamentals, Evolving Technologies, and Emerging Applications. CRC press.

Lin, C.-Y. and Chang, Y.-M. (2014). Increase in physical activities in kindergarten children with cerebral palsy by employing makey-makey-based task systems. Research in developmental disabilities, 35(9):1963-1969.

Moreira, E. and Baranauskas, M. C. (2015). Tecnologias tangíveis e vestíveis como recursos para ambiente inclusivo: uma revisão sistemática. In Anais do Simpósio Brasileiro de Informática na Educação, volume 26, page 842.

Stephanidis, C. and Savidis, A. (2001). Universal access in the information society: methods, tools, and interaction technologies. Universal access in the information society, 1(1):40-55.

Zuckerman, O., Arida, S., and Resnick, M. (2005). Extending tangible interfaces for education: digital montessori-inspired manipulatives. In Proceedings of the SIGCHI conference on Human factors in computing systems, pages 859-868. ACM. 